Salivary gland tumors are rare and account for $2-3 \%$ of tumors occurring in the head and neck. Pleomorphic adenoma is a benign neoplasm which is commonly encountered in the parotid gland and other major salivary glands. At times they can also develop in minor salivary glands of the palate. The majority of minor salivary gland tumors are malignant. This case report describes a case of mixed tumor in a minor salivary gland of the hard palate.

Key words: pleomorphic adenoma, minor salivary gland tumor, palate, surgical treatment.

\section{Pleomorphic adenoma of the palate: a case report and review of the literature}

Mansur Rahnama, Urszula Orzędała-Koszel, Łukasz Czupkałło, Michał Łobacz

Chair and Department of Oral Surgery, Medical University of Lublin

\section{Introduction}

Pleomorphic adenoma (PA) is the most common neoplasm of the large salivary glands and affects mostly the parotid gland, less frequently the accessory salivary glands. It derives its name from the architectural pleomorphism seen by light microscopy. It is also known as "mixed tumor, salivary gland type", which describes its pleomorphic appearance as opposed to its dual origin from epithelial and myoepithelial elements. Mixed tumor accounts for $73 \%$ of all salivary gland tumors. Corresponding to small glands, the palate is the most common site for mixed tumor. Another region that is frequently affected by the tumor is the lips. A small minority of tumors are located in the oral cavity, neck and nasal cavity [1-3]. Other intraoral sites include the buccal mucosa, tongue, floor of mouth, tonsil, pharynx, retromolar area, gingiva and nasal cavity $[1,4]$. Pleomorphic adenomas may occur at any age, but mainly they affect patients in the fourth, fifth and sixth decades. Forty percent of them are male, $60 \%$ female [5]. It also ranks as the most common salivary gland neoplasm in children, representing 66-90\% of all salivary gland tumors [6]. Wide local excision with removal of periosteum and involved bone is the treatment of choice [1, 2]. The potential risk of the PA becoming malignant is about $6 \%$ [7]. Pleomorphic adenoma tumors are painless, well-delineated and covered with normal mucous membrane. Sometimes mucosal ulcerations are observed. Related nodules are singular and mobile. Major gland tumors are usually encapsulated, as opposed to minor gland tumors [2].

Research proves epithelial origin of the mixed tumor, as well as clonal chromosome abnormalities with aberrations involving $8 q 12$ and 12q15 [3]. The tumor often displays characteristic chromosomal translocations between chromosomes \#3 and \#8. This causes the PLAG gene to be juxtaposed to the gene for $\beta$-catenin. This activates the catenin pathway and leads to inappropriate cell division.

\section{Case report}

A 47-year-old female patient was admitted to the Chair and Department of Oral Surgery in the Medical University of Lublin, complaining about a painless swelling on the hard palate. History revealed that the swelling was detected 20 years ago. The tumor was growing slowly. Intraoral examination revealed an oval-shaped, circumscribed lesion, adherent to the underlying structures, covered with slightly erythematous palatal mucosa (Fig. 1). The size of this lesion was about $2 \mathrm{~cm}$ in diameter. The submandibular lymph nodes on the left side were enlarged, painful and movable. The swelling extended from the mid-palatal area to the left alveolar ridge. The overlying mucosa was smooth and intact, but was stretched and thus shiny in comparison with the healthy area on the opposite site of the palate. The checkup orthopantomogram (Fig. 2) did not reveal pathological changes in the bone structures and then due to the clinical examination, outlook and the history of the disease the decision concerning surgical excision of the lesion was made. Excision of the mass was done under anesthesia (Fig. 3). The whole tumor mass was separated out with careful dis- 


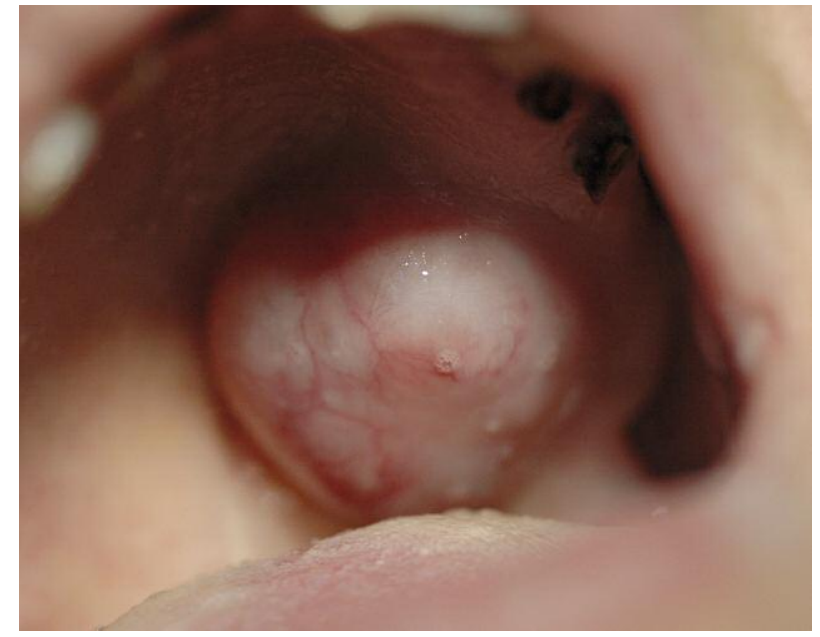

Fig. 1. A diffuse swelling over the left side of the hard and soft palate

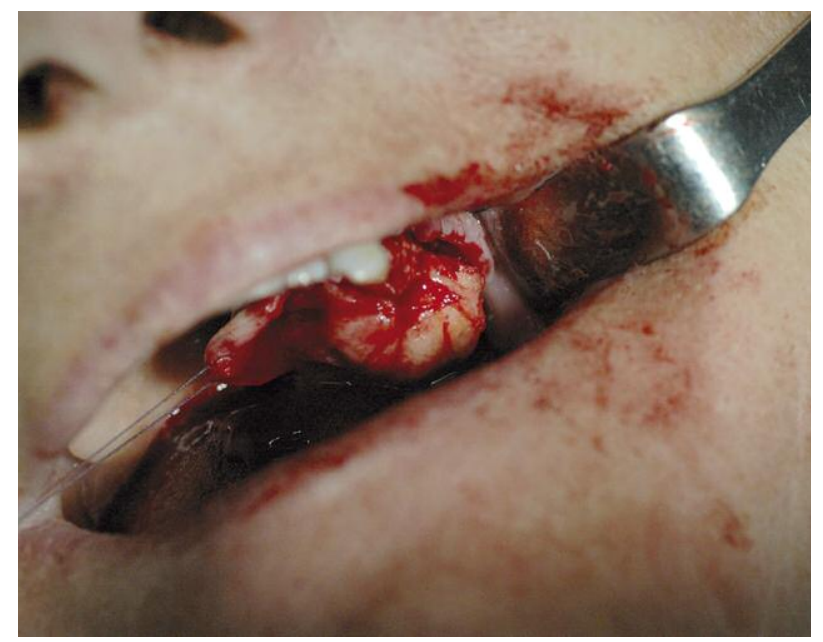

Fig. 3. Surgical procedure

section. Mucosa around the lesion was marked and incised using the surgical blade. Then the wide dissection was performed and the whole encapsulated tumor mass was excised (Fig. 4) along with the mucoperiosteum and the eroded bone

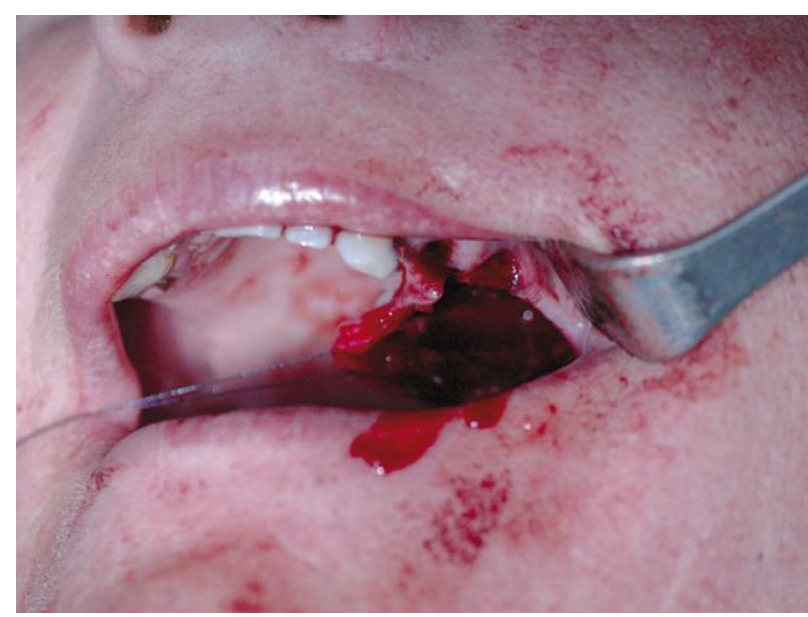

Fig. 5. The operating site after surgical excision of the tumor causing oro-antral communication

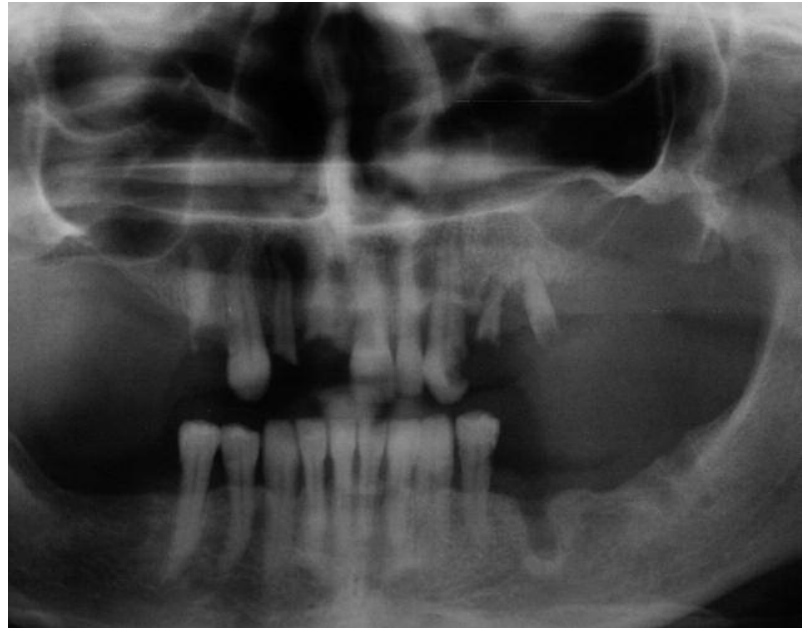

Fig. 2. Orthopantomogram showing lesion involving the left side of the hard palate

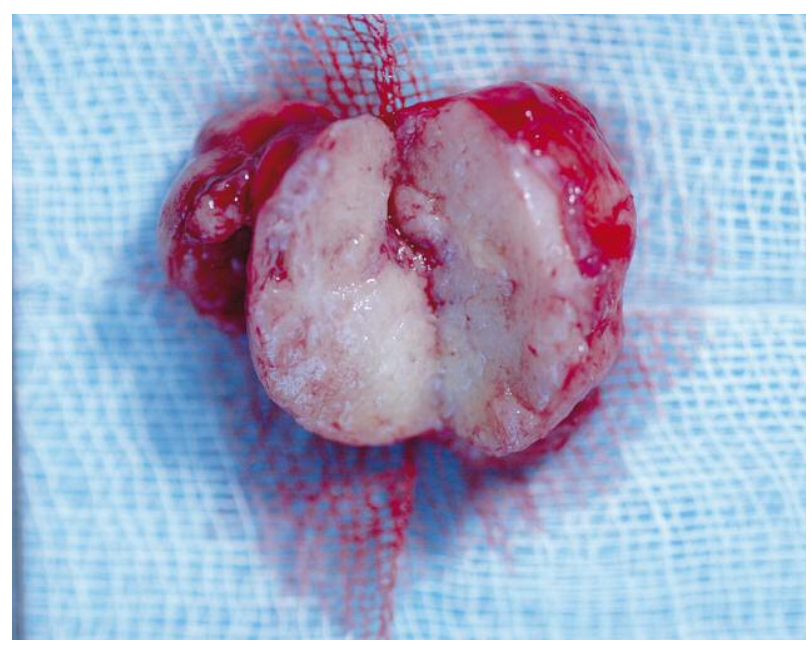

Fig. 4. Surgically excised lesion

of the palate with the boundary line localized in the surrounding healthy tissue (Fig. 5). Hemostasis was achieved by use of electrosurgery. The oro-antral communication that came into existence after the dissection of the tumor was supplied with plastic surgery by the Wassmund-Borusiewicz method. The wound was sutured and the mass sent for histopathological examination. The result of the histopathological examination after the tumor excision (histopathological examination \#77173) was compliant with the specimen taken before the surgery and confirmed the diagnosis of pleomorphic adenoma. The patient's postoperative course was uneventful. No recurrence was observed after a follow-up of 1.5 years.

\section{Discussion}

Tumors occurring in the small salivary glands account for $20-40 \%$ of all salivary gland tumors, precisely $22 \%$, according to Spiro [8].

The smaller the salivary gland that is affected, the more likely it is to trigger a malignant tumor [9]. Mixed tumor of the minor salivary glands affects mostly patients in their fourth to sixth decades, with a predominance of females. 
Clinically pleomorphic adenoma presents as a slow-growing, asymptomatic, unilateral firm mass that may become large if is untreated. When originating in the minor salivary glands, in most cases it occurs on the soft and hard palate due to the highest concentration of salivary glands there and is typically a firm or rubbery submucosal mass without ulceration or surrounding ulceration $[5,10]$.

Histologically, it is highly variable in appearance. Classically it is biphasic and is characterized by a mixture of polygonal epithelial and spindle-shaped myoepithelial elements in a variable background stroma that may be mucoid, myxoid, cartilaginous or hyaline [11]. Epithelial elements may be arranged in duct-like structures, sheets, clumps or interlacing strands and consist of polygonal, spindle or stellate-shaped cells. Areas of squamous metaplasia and epithelial pearls may occur. The tumor is not enveloped, but is surrounded by a fibrous pseudocapsule of varying thickness. The tumor extends through normal glandular parenchyma in the form of finger-like pseudopodia, but this is not a sign of malignant transformation $[11,12]$.

Each tumor shares with others the essential feature of being composed of both epithelial and mesenchymal-like tissues. The proportion of each of these elements varies widely and one or the other is often predominant. The "cellular" type of pleomorphic adenoma is one in which the epithelial element predominates, whereas the "myxoid" type is composed mostly of a myxomatous or myxochondromatous mesenchymal-like element. The "mixed" type is a classic form. Distinctive epithelial cell types include spindle, clear, squamous, basaloid, cuboidal, plasmacytoid, oncocytic, mucous and sebaceous $[11,13,14]$.

The diagnosis of pleomorphic adenoma is established on the basis of history, physical examination, cytology and histopathology. An incisional biopsy must be performed to determine the proper management regimen and treatment $[15,16]$. Computed tomography scan and MRI can provide information on the location and size of the tumor and extension to surrounding superficial and deep structures [17]. Fine-needle aspiration cytology and incisional biopsy can aid in the diagnosis. The treatment is strictly wide local excision with the removal of periosteum or bone if they are involved $[2,18]$.

The differential diagnosis for this case includes palatal abscesses, odontogenic and non-odontogenic cysts, soft tissue tumors such as fibroma, lipoma, neurofibroma, neurilemmoma, and lymphoma as well as other salivary gland tumors [18].

Palatal abscess could be ruled out by clinical examination since the source of a palatal abscess, which is typically a nonvital tooth in the vicinity or a localized periodontal defect, was not found. Both odontogenic and non-odontogenic cysts could be ruled out at the time of exploration into the mass since it did not demonstrate a cystic nature. Palatal tissues contain components of soft tissue and harbor minor salivary gland tissues. Myoepithelioma is a benign epithelial salivary gland tumor, having plasmacytoid or spindled myoepithelial cells [18, A].

Differentiation between benign and malignant tumors is not possible without histopathology [3]. Enucleation of pleomorphic adenomas leads to a high recurrence rate, so it should be avoided.
Surgical exposure of the tumor or tumor capsule risks spillage and dramatically increases the risk of recurrence, but pleomorphic adenomas of the minor glands have little propensity for recurrence (a recurrence rate of 2 to $44 \%$, but mainly of the parotid gland). Recurrent pleomorphic adenomas often form multiple, separate nodules within the remaining salivary gland, periparotid tissues, dermis, or scar tissue even a few or dozen years after the initial surgery. Inadequate surgical procedure was reported to be the main cause of failure. The most frequent surgical issues are pseudopodia, capsular penetration and tumor rupture. Distant metastases are also possible $[2,19]$.

Fifty percent of all tumors derived from the minor salivary glands are reported to be malignant, adenoid cystic carcinoma being the most malignant tumor. Pleomorphic adenomas of the minor salivary glands, like those on the palate, buccal mucosa or lip, sometimes lack encapsulations and may mix into normal host tissue as tumor growth; hence a wide excision is necessary even if previous biopsies report benign nature. If pleomorphic adenoma is located in the superficial lobe of the parotid gland, an effective way of treatment is superficial parotidectomy. When the tumor is located in the deep lobe of the parotid gland, the method of choice is total parotidectomy [20, 21].

Reconstruction of the palate is a challenging endeavor. As with any defect, thinking about the goals of reconstruction from both a functional and esthetic point of view will help decide which approach is most suitable for the patient. Soft tissue defects of the hard palate are essentially a nonissue, as the hard palate can be left to granulate. Bony defects in a dentate patient can be treated conservatively with an obturator. Bony defects of the upper alveolar ridge will cause a significant cosmetic and functional deformity, and therefore free tissue transfer techniques will augment the anterior projection of the face and the soft tissue can be used to seal the oral cavity from the nose. Each technique has its advantages and disadvantages. The goal of maintaining speech, swallowing and anterior facial projection should be kept at the forefront of each surgeon's mind when approaching these difficult cases [22].

In conclusion:

1. Most salivary gland tumors should be dissected due to the possibility of becoming malignant.

2. Wide excision with negative margins is the optimal strategy for the management of pleomorphic adenomas due to occasional lack of encapsulation, mixing into normal host tissue and pseudopodia. A histopathological biopsy should be routinely taken after the excision of the neoplastic lesion.

3. Adequate surgical excision corresponds with lower risk of recurrence.

\section{References}

1. Byakodi S, Charanthimath S, Hiremath S, Kashalika JJ. Pleomorphic adenoma of palate: a case report. Int J Dent Case Reports 2011; 1: 36-40.

2. Bartkowski SB. Chirurgia szczękowo-twarzowa. Collegium Medicum UJ, Kraków 1996.

3. Shrestha A, Reddy NS, Ganguly SN. J Coll Med Sci (Nepal) 2010; 6: 51-3. 
4. Kumar SS, Reddy PS, Prabhakar G. Pleomorphic adenoma of the nasal septum - case report. Indian J Pathol Microbiol 2004; 47: 397-8.

5. Vellios F, Shafer WG. Tumors of minor salivary glands. Surg Gynecol Obstet 1959; 108: 450-6.

6. Callender DL, Frankenthaler RA, Luna MA, Lee SS, Goepfert H. Salivary gland neoplasms in children. Arch Otolaryngol Head Neck Surg 1992; 118: 472-6.

7. Sołkiewicz E, Grajewski S, Sokalski. Guz mieszany w małym gruczole ślinowym policzka - opis przypadku. Implantoprotetyka 2008; 1: 57-8.

8. Spiro RH. Salivary neoplasms: overview of a 35-year experience with 2,807 patients. Head Neck Surg 1986; 8: 177-84.

9. Kopeć T. Nowotwory gruczołów ślinowych. Kamica gruczołów ślinowych. Przew Lek 2002; 5: 78-81.

10. Ledesma-Montes C, Garces-Ortiz M. Salivary gland tumours in a Mexican sample. A retrospective study. Med Oral 2002; 7: 324-30.

11. Kawahara A, Harada H, Kage M, Yokoyama T, Kojiro M. Characterization of the epithelial components in pleomorphic adenoma of the salivary gland. Acta Cytol 2002; 46: 1095-100.

12. Stennert E, Guntinas-Lichius O, Klussmann JP, Arnold G. Histopathology of pleomorphic adenoma in the parotid gland: a prospective unselected series of 100 cases. Laryngoscope 2001; 111: 2195-200.

13. Mendenhall WM, Mendenhall CM, Werning JW, Malyapa RS, Men denhall NP. Salivary gland pleomorphic adenoma. Am J Clin Onco 2008; 31: 95-9.

14. Ogata H, Ebihara S, Mukai K. Salivary gland neoplasms in children. Jpn J Clin Oncol 1994; 24: 88-93.

15. Cerulli G, Renzi G, Perugini M, Becelli R. Differential diagnosis between adenoid cystic carcinoma and pleomorphic adenoma of the minor salivary glands of palate. J Craniofac Surg 2004; 15: 1056-60.

16. Psychogios G, Alexiou C, Schick B, Papadopoulos T, Iro H. Salivary gland tumor of the hard palate. Laryngorhinootologie 2008; 87: 579-82.

17. Kaur S, Thami GP, Nagarkar NM. Pleomorphic adenoma of the hard palate. Indian J Dermatol Venerol Leprol 2003; 69: 74-5.

18. Sreenivas SD. Pleomorphic adenoma of the palate - a case report. JIDA 2011; 5: 4.

19. Patrick J, Bradley M. Recurrent salivary gland pleomorphic adenoma: Etiology, management and results. Curr Opin Otolaryngol Head Neck Surg 2001; 9: 100-8.

20. Daniels JS, Ali I, Al Bakri IM, Sumangala B. Pleomorphic adenoma of the palate in children and adolescents: A report of 2 cases and review of the literature. J Oral Maxillofac Surg 2007; 65: 541-9.

21. Toida M, Shimokawa K, Makita H, et al. Intraoral minor salivary gland tumors: A clinicopathological study of 82 cases. Int J Oral Maxillofac Surg 2005; 34: 528-32.

22. Watts TL Tumors of the hard palate and upper alveolar ridge, Grand Rounds Presentation, The University of Texas Medical Branch (UTMB), Department of Otolaryngology, April 22, 2011.

\section{Address for correspondence}

\section{tukasz Czupkałto}

Chair and Department of Oral Surgery

Medical University of Lublin

ul. Karmelicka 7

20-081 Lublin, Lublin

e-mail: czupkallo@gmail.com

Submitted: $\quad 25.05 .2012$

Accepted: $\quad 16.10 .2012$ 